FNAL/C--92/77

\title{
Measured Control Characteristics of the Half-Cell 40mm Aperture Magnet String
}

\author{
A. McInturff and R. Flora \\ Fermi National Accelerator Laboratory \\ P.O. Box 500, Batavia, Illinois 60510 \\ J. Weisend, II, C. Dickey and D. Wallis \\ Superconducting Super Collider Laboratory \\ 2550 Beckleymeade Ave, Dallas, Texas 75237
}

March 1992

Presented at the Fourth Annual IISSC Conference, New Orleans, LA, March 4-6, 1992.

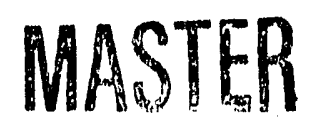




\section{Disclaimer}

This report was prepared as an account of work sponsored by an agency of the United States Government. Neither the United States Government nor any agency thereof, nor any of their employees, makes any warranty, express or implied, or assumes any legal liability or responsibility for the accuracy, completeness, or usefulness of any information, apparatus, product, or process disclosed, or represents that its use would not infringe privately owned rights. Reference herein to any specific commercial product, process, or service by trade name, trademark, manufacturer, or otherwise, does not necessarily constitute or imply its endorsement, recommendation, or favoring by the United States Government or any agency thereof. The views and opinions of authors expressed herein do not necessarily state or reflect those of the United States Government or any agency thereof. 


\title{
MEASURED CONTROL CHARACTERISTICS OF THE HALF-CELL 40MM APERTURE MAGNET STRING
}

\author{
A.D. McInturff, ${ }^{1}$ J.G. Weisend $\mathrm{II}^{2}$, \\ C.E. Dickey, ${ }^{2,3}$ R. Flora, ${ }^{1}$ and D.B. Wallis ${ }^{2}$ \\ Accelerator Division \\ ${ }^{1}$ Ferm: National Accelerator Laboratory* \\ Batavia, Illinois 60510 \\ 2Superconducting Super Collider Laboratory \\ Dallas, Texas 75237 \\ ${ }^{3}$ Dıke University, North Carolina
}

\begin{abstract}
The data presented here were obtained in the course of operating a five $40 \mathrm{~mm}$ aperture dipole string. The eighty eight meter long string of dipoles was assembled to test the various proposed operational scenarios of the SSCL collider. As reported earlier, ${ }^{1}$ there had been a short control and system (data procurement) checkout run performed on an abbreviated two dipole string. The problems that were then uncovered with the exception of the high $20 \mathrm{~K}$ shield heat load, were corrected. There has been over 5000 hours of running time on the system, 3000 hours on the five magnet string alone, and to date, no major problems or incidents have occurred.

The quench (superconducting to normal transition) performance of the magnet string was excellent, with the exception of four premature quenches that occurred during power supply commissioning. The operational parameters were all found to be manageable or equal to or greater than design. The operational heat loads were within the budget with the exception of the $20 \mathrm{~K}$ circuit which was a factor of three too high. The relative internal voltages of the magnets have been higher than previously measured in the shorter string by a significant amount. There will be a discussion of concerns and problems plus their possible solution.
\end{abstract}

\section{INTRODUCTION}

A Superconducting Super Collider "SSC" size tunnel section with a prototype control room, "ER-4" which is capable of operating multiple cells of the "SSC" lattice has been constructed by Fermilab and SSCL personnel near the Tevatron's E-4 service building. There are presently installed and operating five dipoles and a "SPR" spool piece (1/2 cell). The data, however, that will be presented in this paper are for the recently completed five dipole run only. The ER-4 operating system for this particular run consisted of A) computer controlled and monitored $5 \mathrm{Atm}$ ab helium gas refrigerator producing up to 0.6 kilowatt in a $3.8 \mathrm{~K}$ to $5 \mathrm{~K}$ temperature range which used a reciprocating cold compressor; B) an $8.0 \mathrm{kA}$ SSCL prototype inverting computer controlled ${ }^{2}$ power supply creating prototypical accelerator ramps; and C) a quench protection monitor or "QPM"3 which determines the status of the superconducting elements (resistive or not) and their associated systems (i.e., heater firing circuit, security 
gates, power supply, refrigerator, etc.). In addition, to this "ACNET"4 based accelerator control system, there is a stand alone "UNIX" operating environment, Research Instrumentation Data Acquisition System (RIDAS) ${ }^{5}$. This system receives an independent signal from different quench detection circuits "QDC's" which can operate independently by firing the magnet protection heaters in parallel with the "QPM" through a TTL "OR" gate. This data acquisition system can obtain both long term and transient data. The long term system typically measures 140 - 180 plus devices every five minutes. The operator can continuously plot or recall them at his leisure. The high speed circular buffers presently contain 96 channels, although it is possible to expand this in blocks of 32 . The final phase of this experiment is currently underway and includes a spool piece with a recooler, safety leads, quench relief valve, and vacuum break, in addition to the five dipoles. The system protection consists solely of the strip heaters which raise the superconductor in the magnets above their transition temperature.

There were several operational scenarios envisioned for collider operation which were novel and different than those of the present superconducting machines (Tevatron, HERA). Pressures, voltages, temperatures, valve positions, and flows are needed to validate or invalidate the ideas and the various computer code simulations assumptions.

\section{EXPERIMENTAL PROCEDURE}

The primary test objective is to verify that "SSC" magnets can be installed, leak checked, cooled to LHe temperatures, energized in an acceleration cycle, and quenched repeatedly as a string in a tunnel type environment. There were secondary objectives which involve various sub-systems, developments, operating parameters, and scenarios, and above all, gaining operational system experience with these devices. The experimental objectives can be divided as follows: A) refrigeration requirements and control, B) powering parameters and control, C) installation, and D) quench control and prevention. The operating accelerator control system was similar to that of an upgraded Tevatron, except where there were systems far enough along in development by SSCL to be employed. An example of this was replacing the FNAL low ' $B$ ' quad prototype with an SSCL $8 \mathrm{kA}$ inverting power supply. The string magnets have been individually tested. After reception at ER, they are mechanically and electrically checked at room temperature and compared with the previous test results. These tests include vacuum, physical inspection, high voltage (insulation integrity), continuity, inductance and resistance checks, as well as voltage tap position verification. The magnets were then modified for string use. The modifications included installation of magnet/magnet interconnect busses and instrumentation busses and the unblocking of cooling passages (removed cross flow plugs).

The magnets were only roughly aligned (about an order of magnitude less accurate than required for machine operation) for mechanical purposes, in that it was not envisioned to accept beam. Once the magnets were in place and electrically connected, the first of three electrical checks were made. Then after passing the first electrical check, all leads were strain relieved, checked for contraction clearance, then insulated, with the interconnect bellows pulled into place, but not welded. At this point, the power circuits were high potted and the second complete electrical check out was made. The various cryogen circuits are then welded and the vacuum vessel is closed as a high pressure (21.5 Atm) pneumatic test if tile cold mass/liquid helium return line is performed. The circuits are simultaneously vacuum leak checked and certified tight.

The cooldown to final operating parameters of $4.35 \mathrm{~K}, 5 \mathrm{Atm}$ ab, and $50 \mathrm{~g} / \mathrm{sec}$ of gaseous helium was periormed uneventfully. The rate is governed by a $100 \mathrm{~K}$ temperature gradient limit across any device. The daily power-up check list is similar to an operating accelerator including personnel lockout procedures. The string was powered in a stepwise fashion. This enables the operator to estimate fairly accurately, the worse case scenario to be encountered during the next current increase using the data from the last. The cryogenic load data were continually refined throughout the run. The observed thermal equilibrium time constants were measured in hours and/or days. The heat load data was obtained using the $\mathrm{VXI}^{5}$ based data acquisition system. It recorded temperatures, pressures, flows, and strains every five minutes throughout the five month run.

The various cryogenic circuit heat loads were determined by observing the temperature gradient across the string and point to point, at a given gas flow rate. Flow rates were 
determined or cross-checked in two ways. The primary method used a precision gas volume meter versus time. The second was to put a known local load into one of the systems resiscors and note the increase in temperature. The various interconnects were instrumented to determine their gradients. The heat loads of interest were with the cryostat circuits near or at operational temperatures, i.e., $80 \mathrm{~K}$ at $80 \mathrm{~K}, 20 \mathrm{~K}$ at $20 \mathrm{~K}$ and cold mass at $4.3 \mathrm{~K}$. There were, however, different cryogenic loads determined with the various circuits at non-operational temperatures.

There were five spontaneous quenches during the course of testing. These were: $5700 \mathrm{~A}$ DO27, 6145A DO26, 6290 DO201, 6370 DO27, and 6550 DO27. DO27 quenches were in the outer coils. There were a total of 19 strip heater induced quenches that were operator initiated. A total of 29 quenches or power trips (phase back) occurred during the run. Some of these occurred while exploring various operating parameter's ranges like lead flow rates. In all but one case, there were data acquired by three high speed (two 1 kilohertz and one 10 hertz) CAMAC Data Loggers and a four channel 100 kilohertz storage scope. There is also a $60 \mathrm{~Hz}$ circular buffer in the QPM system. It recorded all of the events with the excention of a few of the power supply phase backs.

The main electrical power circuit contains four terminals. Normally, the two leads at the return can were shorted. All of the dipoles were in series on the same buss. (NOTE: this configuration should result in the highest voltages). The "QPM" monitored coil halves to decide when and where a quench had occurred. The "RIDAS" system monitored all but one of the quarter coil voltages. The system was ramped at an accelerator cycle rate 3 times faster than the one proposed for the collider. Therefore the number of cycles obtained in a given time period increased. Collider peak energy stability studies were done. The criteria used was that the system came to equilibrium and stayed there for longer than 4 hours. There were a series of above peak operating field induced quenches. The valve configuration for relief of the quench pressure was systematically changed in order to explore different operating scenarios. Each of the operating relief va' res had a pressure transducer and thermometer near their outlets. (NOTE: the coded safety valves are a different set of valves). See Figure 1. These valves had the following operating modes: A) they opened when the internal pressure exceeded the backing pressure (Kautzky6 type valves), and $B$ ) they could be operated by venting the backing pressure on the signal from the QDC's. Those modes could be additionally modified either to stay open or to reclose once the internal pressure is less than the backing pressure. The valves had two different outlet circuits. They could vent into either: $A$ ) the warm helium gas return line to the suction side of the compressors, or $\mathrm{B}$ ) the $20 \mathrm{~K}$ helium gas circuit at either the return can or to the $20 \mathrm{~K}$ point in the refrigerator heat exchanger. The number of valves activated varied from all six to one valve only for the entire half cell.

Quench recovery was also briefly studied. The Tevatron's Central Refrigerator's iiquid transfer line could be opened after the quench pressure subsided. The transfer simulates the enthalpy of the remainder of the machine (collider) being utilized to speed up recovery.

\section{RESULTS}

The deficiencies encountered during the two dipole assembly, specifically, the longitudinal stability of the shield and the multilayer insulation (MLI), were apparently solved as evidenced by their absence in the five dipole run. The interconnect that was disassembled for the installation of the "SPR" spool for the present run was in the same configuration as before the start of the run. The stability and suitability of the interconnect was also evidenced by the very small temperature gradients measured across the interconnects. There had been concerns about the vacuum in between layers in the "MLI". Therefore, thermometers were placed in between "MLI" layers of the two $80 \mathrm{~K}$ shield blankets. The temperature gradient appeared to be linear with layer number. Therefore, the heat flow was dominated by conductance (through the aluminized mylar).

The cooldown rate was primarily determined by experimental constraints. The first was the $100 \mathrm{~K}$ maximum gradient across any given magnet. The second was the hold at $100 \mathrm{~K}$ and $20 \mathrm{~K}$ for electrical measurements. The actual cooldown to $80 \mathrm{~K}$ was 3.3 days for the 70 ton string. No voltage taps and only three devices failed during the cooldown cycle. The system went through various calibration tests and electrical verification steps at temperature. The thermal load was determined for the various circuits, i.e., $80 \mathrm{~K}$ and $20 \mathrm{~K}$, but not the cold mass 


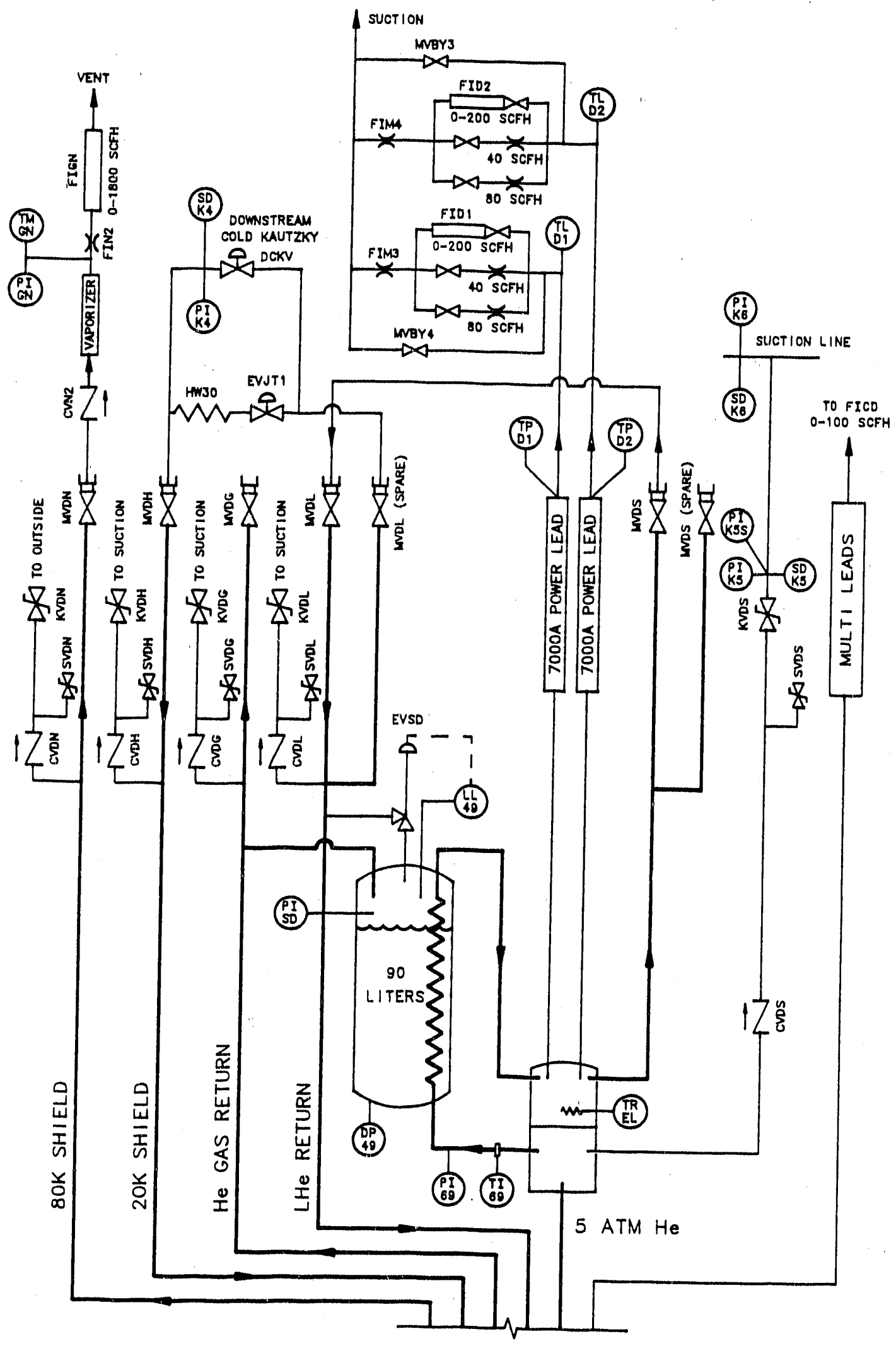

Figure 1. This is a schematic drawing of the valves and circuit flow in the return can. These circuits are to the left of those in Figure 2 and connected one to one, i.e., $20 \mathrm{~K}$ to $20 \mathrm{~K}$ shield. The "Kautzky" valves ("KV") are the quench activated valves as described in the text. The "SV" valves are the "coded" relief valves and as such not operation valves. 


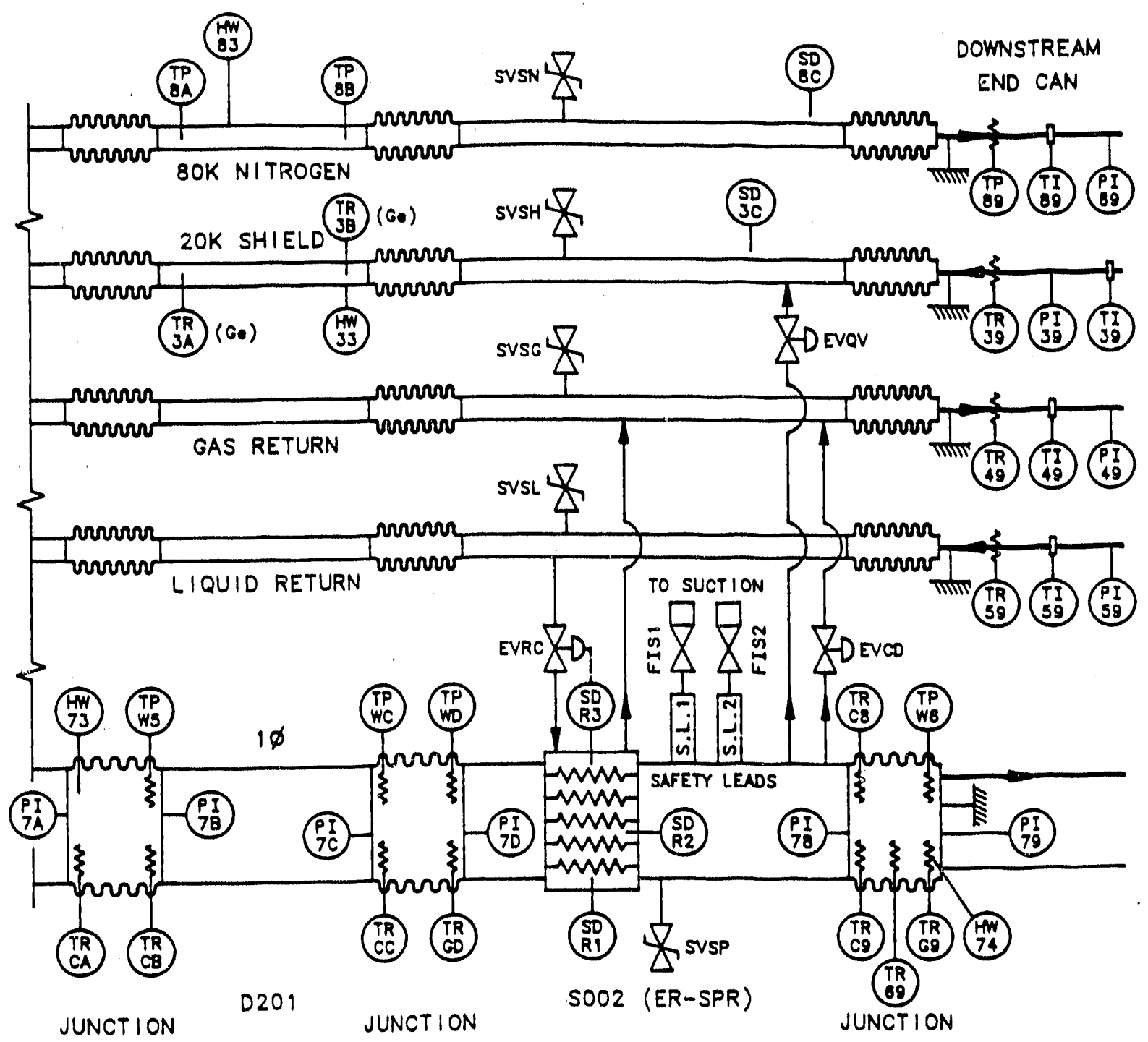

Figure 2. This is an instrumentation diagram of a part of the $40 \mathrm{~mm}$ aperture $1 / 2$ cell. It contains most of the types of devices used. (HW = heater; $\mathrm{PI}=$ pressure indicator, 70 series are cold sensors all other PI's are room temperature); $\mathrm{SD}=$ silicon diode; $\mathrm{SG}=$ strain gage; $\mathrm{TI}=$ vapor bulb thermometer; $\mathrm{TL}=$ cryogenic linear temperature sensor; $\mathrm{TP}=$ platinum resistance thermometer; $T R=$ thermometers (30 seri 1 are Ge resistors, 40,50, and 60 series are carbon resistors), or C series are carbon glass resistors, $G$ series are germanium resistors, SDR series are silicon diodes located in the recooler.

(although it was bracketed just to determine the measurement range). The various cryogenic circuit heat loads resulted in gradients across the string of degrees. The cold mass circuit was an exception where it was about $1.5 \mathrm{~K}$ with an uncertainty of a quarter of a degree. The temperature variation at a given point was equal to or less than a couple of tenths of a degree. The temperature variation at the inlet or the outlet was on the order of a degree. The largest measurement uncertainty was the flow determination which was cross checked by introduction of a load and observing the temperature increase. This check resulted in a discrepancy of about $20 \%$. This maybe a result of incomplete mixing, i.e., stratification. In the cold mass, only the "known" load method was used to determine the flow. The heat load data are presented in Table 1.

The typical instrumentation package of the string is shown in Figure 2. It can be seen that there was ample redundancy in most sensors, to enable the operator to ider.tify an erroneous device and correct it.

The string field level was raised in a step wise fashion to the peak operating value. Therefore data from previously induced strip heater quenches could be used to predict the parameters during the next induced higher current quench. Unlike the previous run, spontaneous training quenches were encountered during this phase. These premature 
TABLE 1- Heat Load Summary (Heat load represents 1 dipole plus interconnect)

80K SHIELD

This is with the $20 \mathrm{~K}$ shield operating at $20 \pm 1 \mathrm{~K} \mathrm{~T}$ av $(18 \mathrm{~K}-23 \mathrm{~K})$. The cold mass temperature was between 4.5 to $4.3 \mathrm{~K}$. The temperature range of the $80 \mathrm{~K}$ shield was between $99 \mathrm{~K}$ and $131 \mathrm{~K}$.

$\begin{array}{lllllll}\text { Budget } & \text { Flow } & \text { D } 17 & \text { D026 } & \text { D019 } & \text { DO27 } & \text { D201 } \\ 27 \mathrm{~W} & 3.3 \mathrm{~g} / \mathrm{sec} & 18.2 \pm 2 \mathrm{~W} & 17.2 \pm 2 \mathrm{~W} & 31.0 \pm 2 \mathrm{~W} & 23.0 \pm 2 \mathrm{~W} & 28.0 \pm 2 \mathrm{~W}\end{array}$

20K SHIELD

This is with the $80 \mathrm{~K}$ shield operating at $78-80 \mathrm{~K}$ and the cold mass temperature between $4.5 \mathrm{~K}$ 4.3K. The temperature range of the $20 \mathrm{~K}$ shield was between $20 \mathrm{~K}-25 \mathrm{~K}$.
Budget
Flow
D017
D026
D019
D027
D201
3.3W
$0.85 \mathrm{~g} / \mathrm{sec}$
$12.9 \pm 3.0 \mathrm{~W}$
$6.4 \pm 2.0 \mathrm{~W}$
$7.0 \pm 1.5 \mathrm{~W}$
$9.0 \pm 2.0 \mathrm{~W}$
$6.0 \pm 2.0 \mathrm{~W}$

Cold Mass Range Estimate

The $80 \mathrm{~K}$ shield at $79 \mathrm{~K}-80 \mathrm{~K}$ and the $20 \mathrm{~K}$ shield between $19 \mathrm{~K}-22 \mathrm{~K}$. The cold mass temperature was $4.6 \mathrm{~K}$.
Budget
Flow
$0.280 W^{*}$
$(4.84-2.4 \mathrm{~g} / \mathrm{sec})$
Average load $=$ Magnet + Interconnect
$0.3 \mathrm{~W} \pm .2 \mathrm{~W}$

*This does not represent the major load which is an order of magnitude larger, namely the synchrotron radiation load.

transitions resulted in the highest operational voltages recorded to date. All but one of these quenches however occurred at $\geq 95 \%$ of maximum operational field. The QDC's and QPM's, both diagnosed the presence of resistance accurately, and early. The "QPM" initiated the protection strip heater firings. The resulting resistance brought the current down rapidly enough not to unduly heat the windings. In Table 2, the events (data taken) are listed as well as their "MIITS" (million ampere squared seconds) if applicable. The delay time is the period between heater firing and the coil volume under them becoming resistive. The voltage listed is either with respect to ground or if it is in parenthesis () with respect to another coil.

The primary quench experiment objective was to measure the pressures produced in the system and their time profiles. The other parameters of interest included voltage to ground, coil temperatures, and coil to coil voltages. Toward the end of the studies, a brief look at recovery was taken. Recovery means the cold mass parameters are such that powering to full field is possible. Figure 3 shows the intermagnet pressure as a function of time. There are various valve scenarios plotted. They are: (see Figure 1) A) all "Kautzky" valves (K type) opened and held open for 1 minute, KVUL, KVDL, KVDS, KVUS, feedcan cold Kautzky, $=U C K V ", D C K V ; B$ ) all valves (K type) opened at the feed can and held open for 1 minute; $C$ ) both cold valves (20K shield, UCKV and DCKV) are opened but not held open; D) both cold valves are opened and held 1 minute; and E) one cold valve, (DCKV) opened and held for 1 minute. The important observation here is that it is adc quate to have only one cold quench relief valve per half cell. The maximum pressure differential across the five magnet string was less than $140 \mathrm{kPa}$ and the maximum pressure was $1.25 \mathrm{MPa}$. It appears if there are two valves of this type, and one fails and only one valve per cell opens, it will be sufficient. The reason for these low pressure increases is explained by the temperature measured with the exhaust line diodes. The $20 \mathrm{~K}$ line diode has lowered to $<5 \mathrm{~K}$ after $300 \mathrm{~ms}$ (about coincident with pressure peak). It only takes about 10 seconds for the warm header diode to reach $<6 \mathrm{~K}$ near the outlet. These very low temperatures create a high conductance through the valves, therefore, the low pressure drops.

The operational result that presents a problem is the high voltages encountered during the spontaneous quenches. This is partially due to the small coil volume affected by the protection strip heaters. The coils had distributed spot heaters along the heater strips. This requires the quench to propagate both longitudinally and tangently. The $50 \mathrm{~mm}$ magnet heaters have double the number of turns and larger lengths of each turn under the heater. It is also planned, in the accelerator, to split the dipoles - three on upper buss and two on the lower buss. This combination should lead to lower overall voltages.

The only comment that can be made about quench recovery was that it expedited recovery if the quench valve was left open at least for 1 minute after the quench. When the peak liquid 
TABLE 2 - Quench/Phase Back Event Listing

$\begin{array}{llllcc}\text { Event } & \text { Current } & \text { Description } & \text { MIITS } & \begin{array}{c}\text { Delay } \\ \text { (Sec) }\end{array} & \begin{array}{c}\text { Voltage } \\ \text { Ground or } \\ \text { (Relative) } \\ (36)\end{array} \\ 1 & 1.3 \mathrm{kA} & \text { Power Supply Trip } & 1.5 & .500 & (60) \\ 2 & 2.0 \mathrm{kA} & \text { Power Lead Trip } & 3.4 & .25 & (1.30) \\ 3 & 3.0 \mathrm{kA} & \text { Strip Heater Initiate } & 3.0 & .14 & (120) \\ 4 & 4.0 \mathrm{kA} & \text { Strip Heater Initiate } & 4.6 & .095 & (250) \\ 5 & 5.0 \mathrm{kA} & \text { Strip Heater Initiate } & 5.86 & .6 & (65) \\ 6 & 2.5 \mathrm{kA} & \text { Power Supply Induced } & 3.4 & .22 & (350) \\ 7 & 5.7 \mathrm{kA} & \text { D27LO Spontaneous } & 10.0 & . .3 & (626) \\ 8 & 6.0 \mathrm{kA} & \text { Strip Heater Initiate } & 6.5 & .09 & 1075 \\ 9 & 6.2 \mathrm{kA} & \text { D26UO Spontaneous } & 8.9 & -.03 & (356) \\ 10 & 6.3 \mathrm{kA} & \text { D201LO Spontaneous } & 9.1 & -.03 & 975(1300) \\ 11 & 6.4 \mathrm{kA} & \text { D27UO Spontaneous } & 9.2 & -.03 & 626 \\ 12-14 * & & & & .09 & 623 \\ 15 & 5.5 \mathrm{kA} & \text { Strip Heater Initiate } & 5.3 & .08 & 663 \\ 16 & 6.0 \mathrm{kA} & \text { Lead Trip Inducted } & 5.1 & .07 & 861 \\ 17 & 6.4 \mathrm{kA} & \text { Transd Failure } & 6.5 & .02 & 635 \\ 18 & 6.6 \mathrm{kA} & \text { D27LO Spontaneous } & 8.7 & .07 & \\ 19 & 6.5 \mathrm{kA} & \text { Refrigerator Trip } & 5.4 & & \\ 20-29 * & & & & & \end{array}$

*COMMENT: Events \#12-14 and \#20-29 the first group, were strip heater induced at a current of $6.5 \mathrm{kA}$, and $6.6 \mathrm{kA}$ in the second. The thermal diffusion time was between 60 and 70 milliseconds. The number of "MIITs" varied from 5.3 to 7.2. The voltage to ground was in the $500 \mathrm{~V}$ to $750 \mathrm{~V}$ range.

flow rate from the central "Tevatron" liquefier was about $500 \mathrm{l} / \mathrm{hr}$, recovery time was about 34 hours. This represents a moderate rate of turnaround (6+ MJ stored), and not the maximum rate (minimum recovery time).

During the disassembly of the interconnect between the last dipole and the return can, the "MLI", the taping, and the shields all seemed to be "as assembled" when compared with the assembly photos. Inside the cold mass a large amount of dust was found which is thought to be grinding wheel remnants and stainless steel chips. In the future only cutting tools should be used for disassembly after individual cryogenic testing. In summary, the operation of the half cell has not encountered any problems that appear difficult enough to prevent the operation of the SSC Collider.

\section{ACKNOWLEDGEMENTS}

The authors would like to recognize the contribution of the various groups and many individuals for the completion of the facility and the actual performance of the various phases of the experiment. There will not be an attempt to order as of merit. The Fermilab technicians, engineers, and scientists include, R. Brooken, T. Cross, S. Hayes, R. Lively, J. Lockwood, M. MacPherson, K. Martin, R. Orr, P. Payne, A. Rehbein, G. Saevent, T. Savoied, J. Theilacker, D. Wolf, and B. West. The SSCL staff includes: R. Applegate, R. Carlone, W. Clay, J. Darby, D. Freeman, K. Goetze, J. Gran, M. Hentges, F. Kelly, J. Morris, D. Musser, R. Nehring, T. Neustadt, T. Reeves, B. Smith, W. Smith, G. Sorenson, G. Tool, D. Voy, and C. White. The data has been independently analyzed by $S$. Augustynowicz, M. Levin, and W. Robinson of SSCL. The instrumentation and installation of interconnect insulation blankets w's done by $R$. Kunzelman, and $R$. Tuskey, directed by W. Boroski (FNAL). There were many others who contributed before the authors were involved and therefore unknown to them. We apologize for any oversights, a general thanks to them as well. 
Cold Mass Quench Pressure

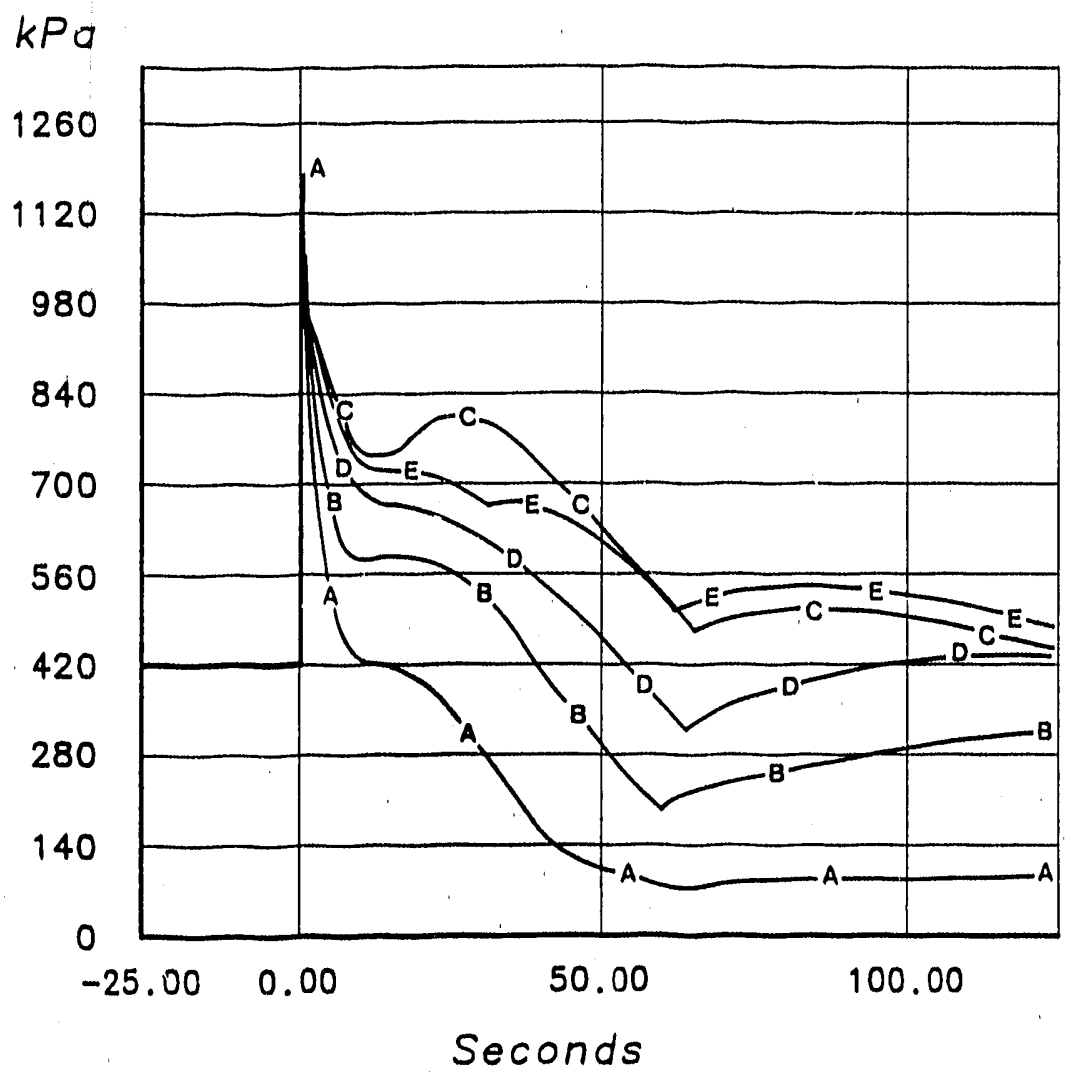

Figure 3. These are plots of pressure measurements, PI75, a cold transducer located in the junction between dipoles DO26 and D019. The valve scenarios are as follows: A) KVUL, KVDL, KVUS, KVDS, UCKV, and DCKV quench activated and held open 1 minute; B) KVUL, KVUS, UCKV, activated and held 1 minute; C) UCKV, DCKV activated; D) UCKV, DCKV activated and held 1 minute; and E) DCKV activated and held 1 minute. See text and Figure 1 for more detailed explanation and system schematic.

\section{REFERENCES}

1. A.D. McInturff, R. Flora, B. Norris, J. Theilacker, D.A. Wolf, S.A. Augustynowicz,C.E. Dickey, G. Tool, D.B. Wallis, and J.G. Weisend II, "Half Cell "SSC" $40 \mathrm{~mm}$ Aperture Magnet String", Proceedings of the Twelfth Int'l. Conference on Magnet Technology, Leningrad, USSR, June, 1991.

2. O. Calvo, R. Flora, M. MacPherson, "Real Time Control of the S3C String Magnets", iEEE Transaction on Nuclear Science. Vol. NS-34, No 4. August, 1987.

3. R.H. Flora and G.S. Tool, "Doubler Tevatron $\mu$ P Quench Protection System", IEEE Transaction on Nuclear Science. Vol. NS-26. No. 3.June, 1979.

4. F.J. Nagy, "The Fermilab Accelerator Controls Networking System", Nuclear instruments and Methods, A247 (1986), P. 208.

5. C. Dickey, D. Wallis, J. Weisend, K. Low, M. Allen, "A VXI Based Data Acquisition and Control System for Super Collider Magnet Systems and String Tests", Proceedings of the Test Engineering Conference, Atlanta, GA, June, 1991.

6. Private communication, Hans Kautzky, Tevatron Relief Valve, which was redesigned and built to ASME Type Safety Code for HERA. The cold relief valve is a modification and redesign for cold operation by $D$. Allspach and $J$. Theilacker (FNAL). 

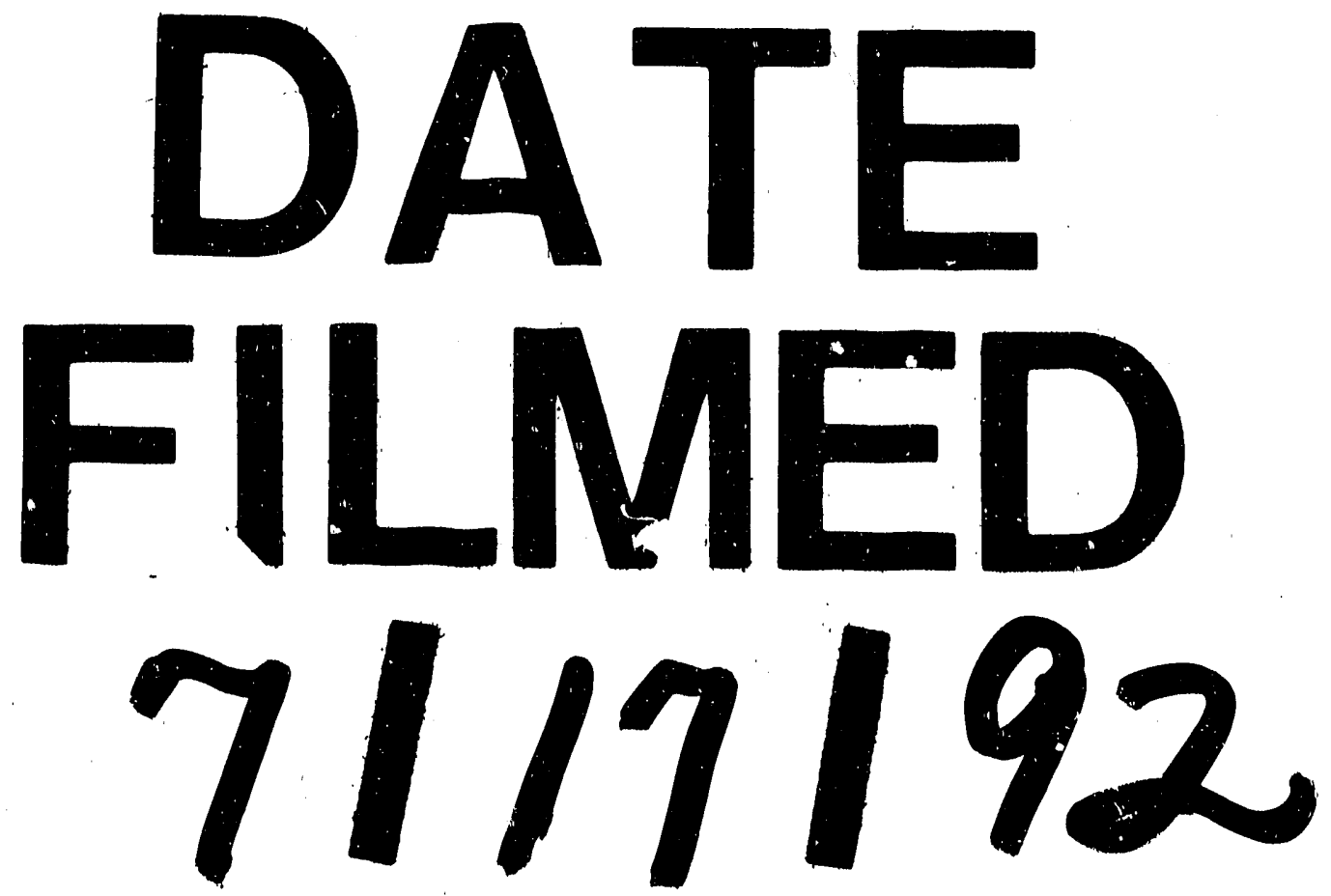


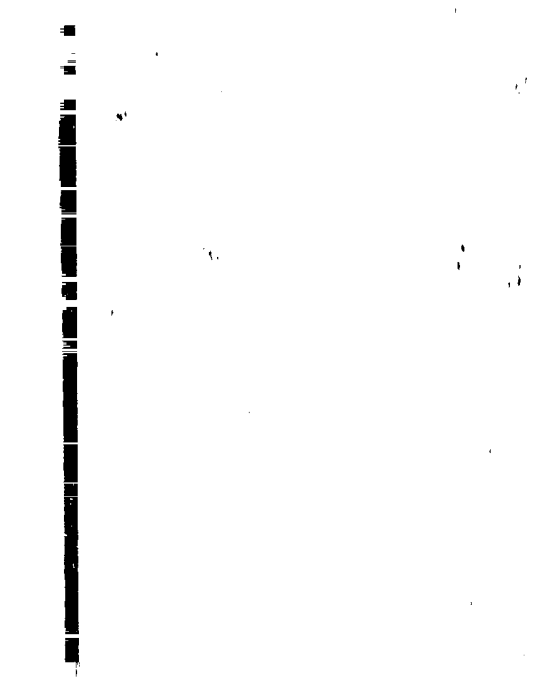

